\title{
Antimutagenicity of Methanolic Extracts from Anemopsis californica in Relation to Their Antioxidant Activity
}

\author{
Carmen Lizette Del-Toro-Sánchez, ${ }^{1}$ Nereyda Bautista-Bautista, ${ }^{2,3}$ José Luis Blasco-Cabal, ${ }^{2}$ \\ Marisela Gonzalez-Ávila, ${ }^{3}$ Melesio Gutiérrez-Lomelí, ${ }^{1}$ and Myriam Arriaga-Alba ${ }^{2}$ \\ ${ }^{1}$ Centro Universitario de la Ciénega, Universidad de Guadalajara, Avenida Universidad 1115, 47820 Ocotlán, JAL, Mexico \\ ${ }^{2}$ Microbiology Research Laboratory, Research Department, Hospital Juárez de México, Avenida Instituto Politécnico \\ Nacional No. 5160, 07760 Ciudad de México, DF, Mexico \\ ${ }^{3}$ Centro de Investigación y Asistencia en Tecnología y Diseño del Estado de Jalisco, A.C. Avenida Normalistas No. 800, Col. \\ Colinas de la Normal, 44270 Guadalajara, JAL, Mexico
}

Correspondence should be addressed to Myriam Arriaga-Alba; arriaga_alba@yahoo.com

Received 22 April 2014; Accepted 24 June 2014; Published 23 July 2014

Academic Editor: Gabino Garrido

Copyright (C 2014 Carmen Lizette Del-Toro-Sánchez et al. This is an open access article distributed under the Creative Commons Attribution License, which permits unrestricted use, distribution, and reproduction in any medium, provided the original work is properly cited.

\begin{abstract}
Anemopsis californica has been used empirically to treat infectious diseases. However, there are no antimutagenic evaluation reports on this plant. The present study evaluated the antioxidant activity in relation to the mutagenic and antimutagenic activity properties of leaf (LME) and stem (SME) methanolic extracts of A. californica collected in the central Mexican state of Querétaro. Antioxidant properties and total phenols of extracts were evaluated using DPPH (1,1-diphenyl-2-picrylhydrazyl) and Folin-Ciocalteu methods, respectively. Mutagenicity was evaluated using the Ames test employing Salmonella enterica serovar Typhimurium strains (TA98, TA100, and TA102), with and without an aroclor 1254 (S9 mixture). Antimutagenesis was performed against mutations induced on the Ames test with MNNG, 2AA, or 4NQO. SME presented the highest antioxidant capacity and total phenolic content. None of the extracts exhibited mutagenicity in the Ames test. The extracts produced a significant reduction in 2AA-induced mutations in S. typhimurium TA98. In both extracts, mutagenesis induced by 4 NQO or methyl- ${ }^{\prime}$-nitro-N-nitrosoguanidine (MNNG) was reduced only if the exposure of strains was $<10 \mu \mathrm{g} /$ Petri dish. A. californca antioxidant properties and its capacity to reduce point mutations render it suitable to enhance medical cancer treatments. The significant effect against antimutagenic 2AA suggests that their consumption would provide protection against carcinogenic polycyclic aromatic compounds.
\end{abstract}

\section{Introduction}

Antimutagenic studies are a good alternative for obtaining important information that explores the possibilities for reducing the genotoxic risk exposure to genotoxic compounds. Many studies of natural plants, such as Stevia pilosa, Stevia eupatoria, and Castela texana, have exhibited antimutagenic and antigenotoxic properties [1, 2]. Among these plants, it has been reported that antioxidants, a mixture of components that can reduce reactive oxygen species (ROS), induce mutagens or improve alkylated DNA damage $[3,4]$. Phenolic compounds serve to improve the antioxidant properties of the plants; thus, they have attracted special attention [5].
The mechanism of mutagenesis is complex. However, many mutagens and carcinogens may act through the generation of ROS [6]. ROS may play a major role as endogenous initiators of degenerative processes, such as DNA damage and mutation. Therefore, the discovery and the exploration of compounds possessing antioxidant and mutagenic properties are of great practical and therapeutic significance [7].

The Salmonella enterica serovar Typhimurium Ames method has been recommended as the first step for initiating a genotoxic risk evaluation for new products to which humans are exposed, mainly for therapeutic drugs. This method has been accepted by several international organizations and these organizations occasionally suspend 
research on new products simply because the product in question produced a positive result on the Ames test [8-12].

Anemopsis californica is a plant of the Saururaceae family; its common name in Mexico is hierba mansa or hierba del manzo $[13,14]$. It grows in the southwestern states of the US and in the northern and central states of Mexico [1517]. In the state of Querétaro (a central state in Mexico), the plant has been found in the swamps of Juriquilla at an altitude of $1,900 \mathrm{~m}$ [18]. It has been widely used in traditional medicine to treat several medical conditions. In some cases, it has been recommended as a treatment for gastric problems, dysmenorrhea, and venereal diseases [19$22]$, as an anticarcinogenic $[23,24]$, and as an antibacterial [25]. The variety of components found in this plant may explain its wide therapeutic uses, some of which are empirically proven [26]. However, to date no antimutagenic evaluations of $A$. californica have been conducted. In this study, we report the evaluation of the antioxidant activity in relation to the mutagenic and antimutagenic properties of LME and SME A. californica collected in the state of Querétaro, Mexico. These studies were performed in order to know the mutagenic and antimutagenic properties of this plant.

\section{Methods}

2.1. Chemicals, Strains, and Animals. 4-Nitroquinoline-1oxide (4NQO), picrolonic acid (PA), methyl- $\mathrm{N}^{\prime}$-nitro-Nnitrosoguanidine (MNNG), 2-aminoanthracene (2AA), cyclophosphamide (CP), 1,1-diphenyl-2-picrylhydrazyl (DPPH), and mitomycin C were obtained from Sigma (St. Louis, MO, USA) and aroclor 1254 was purchased from Supelco (Bellefonte, PA, USA). S. typhimurium strains TA98 (hisD3053, rfa, pKm101, and uvrB), TA100 (hisG46, rfa, pKm101, and $u v r B$ ), and TA102 (hisG 8976, rfa, pkM101, hisG428, $p Q 1$, and $u v \mathrm{rB}+$ ) were kindly donated by Dr. Bruce Ames, University of California, Berkeley. The S9 homogenate fraction of rat liver induced with arochlor 1254 was prepared as described by Maron and Ames [27].

2.2. Anemopsis californica Extract Preparation. Leaves and stems of Anemopsis californica were collected from swamp soil in Querétaro (Mexico) in February of 2012; they were cut and dried separately for $48 \mathrm{~h}$ at $37^{\circ} \mathrm{C}$. The dried material was ground into small particles. Five grams of each sample, either leaves or stems, was mixed with $15 \mathrm{~mL}$ of methanol and homogenized with an Ultraturrax ( $\mathrm{T} 25$ DS1 digital homogenizer) for $1 \mathrm{~min}$. Afterwards, the sample was ultrasonicated (Bransonic, 151-DTH) at $4^{\circ} \mathrm{C}$ for $15 \mathrm{~min}$. The supernatant was collected after centrifugation at $4,000 \mathrm{rpm}$ for $15 \mathrm{~min}$ at $4^{\circ} \mathrm{C}$. The extraction procedure was repeated for a second time. The combined supernatants were evaporated under vacuum conditions at $45-50^{\circ} \mathrm{C}$ (Heidolph Rotavapor, 4003 VAC Senso T) to dryness. The dry extract was solubilized in methanol to a final concentration of $14 \mathrm{mg} / \mathrm{mL}$ [25]. The final extracts were denominated leaf and stem methanolic extracts (LME and SME), respectively.
2.3. Antioxidant Capacity Test. The antioxidant activities were determined using DPPH as a free radical [28]. Different methanolic dilutions of LME and SME $(0.1,0.2,0.43,0.87$, $1.75,3.5,7.0$, and $14 \mathrm{mg} / \mathrm{mL}$ ) were tested. A volume of $0.1 \mathrm{~mL}$ of these extract solutions was added to $3.9 \mathrm{~mL}$ of a $6 \times 10^{-5} \mathrm{~mol} / \mathrm{L}$ DPPH solution. The decrease in absorbance was determined at $515 \mathrm{~nm}$ at 0 and $30 \mathrm{~min}$ under conditions of darkness. The control sample was prepared containing the same volume without any extract. Methanol was used as the blank. All determinations were carried out in triplicate. The results are reported as $\%$ of inhibition with the equation

$\%$ of inhibition

$$
=\frac{\text { (initial absorbance }- \text { final absorbance) }}{\text { initial absorbance }} * 100 .
$$

2.4. Determination of the Total Phenolic Content. Estimation of the total phenolic content was performed as it was reported by others [29-31]; we customized the material for 96-well microplates. LME and SME extracts were diluted in methanol at a ratio of $1: 200$ and $1: 100$, respectively. Gallic acid, prepared in six concentrations ranging from 4 to $20 \mathrm{mg} / \mathrm{L}$, was used as a standard.

Thirty $\mu \mathrm{L}$ of each extract or standard solution, except in a blank probe where only the solvent was used, was added to $150 \mu \mathrm{L}$ of $0.1 \mathrm{~mol} / \mathrm{L}$ Folin-Ciocalteu reagent and mixed with $120 \mu \mathrm{L}$ of sodium carbonate $(7.5 \%)$ after $10 \mathrm{~min}$. Absorbance at $760 \mathrm{~nm}$ was read after $2 \mathrm{~h}$. The phenolic concentration was determined by comparison with the standard calibration curve of gallic acid, and the results are presented as a mean value of triplicate tests. The total phenol value was expressed as $\mathrm{mg}$ of gallic acid equivalents (GAE) per $\mathrm{g}$ of dry weight $(\mathrm{dw})$.

2.5. In Vitro Mutagenesis Assays. S. typhimurium strains, TA98, TA100, or TA102, were incubated with Oxoid nutrient broth number 2 for $16 \mathrm{~h}$ at $37^{\circ} \mathrm{C} / 90 \mathrm{rpm}$. Then, $100 \mu \mathrm{L}$ of the culture was poured into a sterile tube containing a soft agar with $0.5 \mathrm{mM}$ histidine-biotin as described by Maron and Ames [27]. The tester strains were then treated with $250-1,000 \mu \mathrm{g} /$ Petri dish of LME or SME, with or without the S9 mixture. As positive controls, TA98 was exposed to $50 \mu \mathrm{g} /$ Petri dish of (PA) $(10 \mu \mathrm{L}$ of $5 \mu \mathrm{g} / \mu \mathrm{L}$ of (PA)), without $\mathrm{S} 9$, or $10 \mu \mathrm{g} /$ Petri dish of (2AA) $(10 \mu \mathrm{L}$ of $1.0 \mu \mathrm{g} / \mu \mathrm{L}$ of $(2 \mathrm{AA}))$ with S9, TA100 to $10 \mu \mathrm{g} /$ Petri dish of MNNG $(10 \mu \mathrm{L}$ of $1.0 \mu \mathrm{g} / \mu \mathrm{L}$ of MNNG) or $500 \mu \mathrm{g} /$ Petri dish of CP $(10.0 \mu \mathrm{L}$ of $50.0 \mu \mathrm{g} / \mu \mathrm{L}$ of $\mathrm{CP}$ ) with $\mathrm{S} 9$, and TA102 with $10 \mu \mathrm{g} /$ Petri dish of 4NQ0 $(10 \mu \mathrm{L}$ of $1.0 \mu \mathrm{g} / \mu \mathrm{L}$ of $4 \mathrm{NQ} 0)$ with or without S9. They were poured into Vogel-Bonner medium and incubated for $48 \mathrm{~h}$ at $37^{\circ} \mathrm{C}$. Then, histidine revertant colonies were counted with a Fisher-Scientific semiautomatic colony counter. A positive result is given when the number of spontaneous histidine $(+)$ revertants was twice the amount of that of spontaneous reversion.

2.6. In Vitro Antimutagenesis Assays. Antimutagenesis assays were performed using the Ames test as described by Maron and Ames [27]. The first group of studies was conducted by 


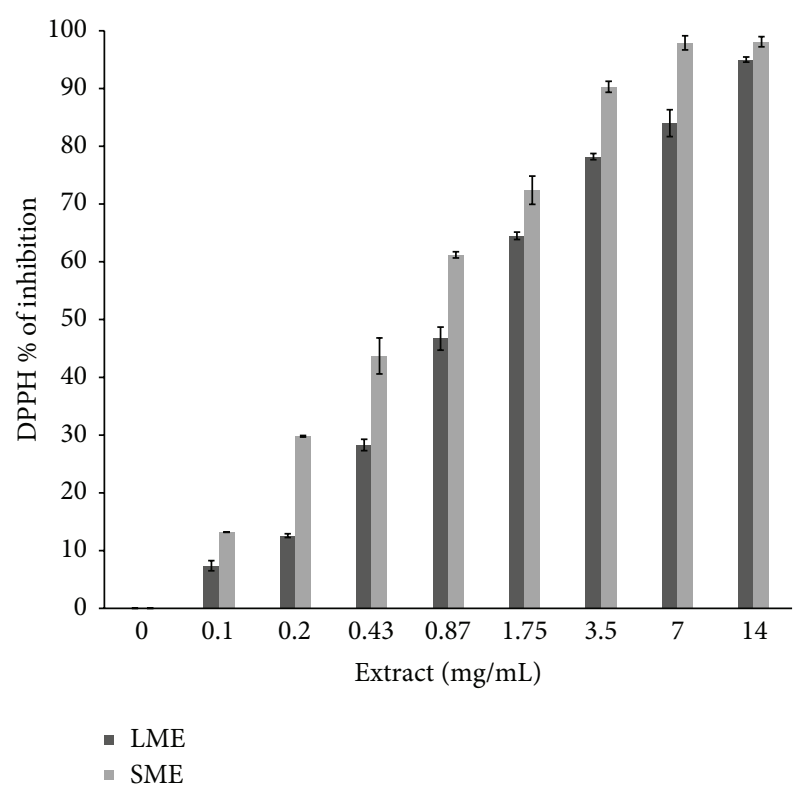

FIGURE 1: DPPH (1,1-diphenyl-2-picrylhydrazyl), antioxidant evaluation with leaves (LME) and stems (SME) of A. californica.

exposing S. typhimurium to the following different mutagens: TA100 to MNNG (5-10 $\mu$ g/Petri dish), S. typhimurium TA98 to $2 \mathrm{AA}(5-10 \mu \mathrm{g} / \mathrm{dish})$ with the aroclor 1254 -induced $\mathrm{S} 9$ mixture (S9 mix), and S. typhimurium TA102 to 4NQNO (5-10 $\mu \mathrm{g} /$ Petri dish). Secondly, the three strains were also exposed to 250 or $500 \mu \mathrm{g}$ of LME and SME without the mutagen and with or without the $\$ 9$ mix [27]. Finally, antimutagenesis was evaluated, exposing each $S$. typhimurium strain to the appropriate dose of mutagens MNNG, 2AA, or 4NQO, plus LME or SME (250 or $500 \mu \mathrm{g} /$ Petri dish), under suitable assay conditions as described previously.

2.7. Statistical Analysis. The results were evaluated using a two-part analysis with Graphic-Presentation Prism version 2.01 software, comparing the reduction of mutations induced only with the positive control with those exposed to both the positive control and the plant extracts.

\section{Results}

3.1. Antioxidant Capacity Test. Figure 1 depicts a dose-curve response with respect to an increase of extract concentration. SME presented more antioxidant activity than LME. Highest antioxidant activity was observed in SME at $7 \mathrm{mg} / \mathrm{mL}$ while LME was $14 \mathrm{mg} / \mathrm{mL}$ (98.1 and 95\%, resp.).

3.2. Total Phenolic Content. The amount of the total phenolics was found to be very different between the stem and leaf of $A$. californica. SME $(79.44 \pm 3.50 \mathrm{mg}$ GAE/g of $\mathrm{dw})$ presented higher total phenols than LME $(27.84 \pm 0.98 \mathrm{mg}$ GAE/g of $\mathrm{dw}$ ). According to the previously mentioned antioxidant results, there was a correlation between total phenolic content and antioxidant activities.

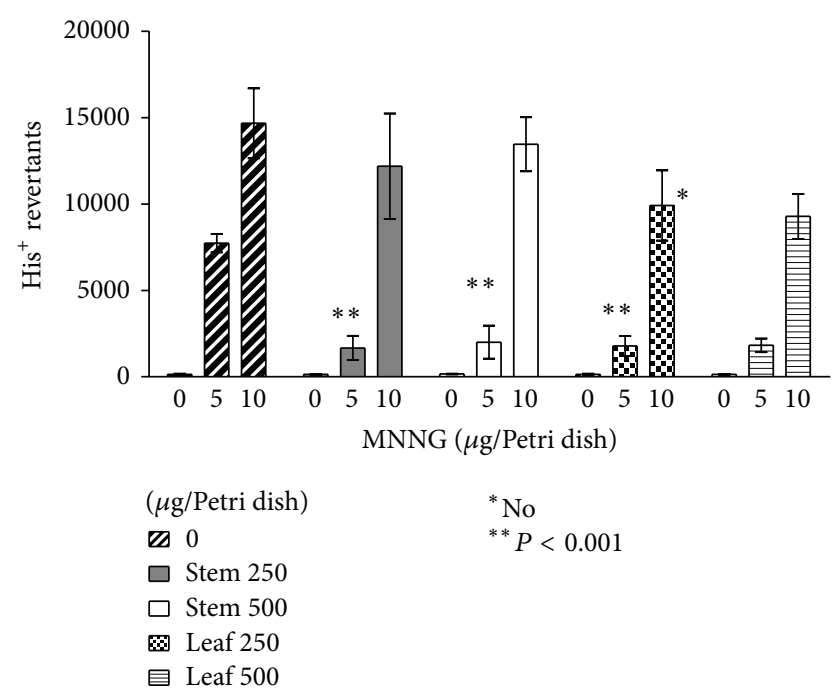

Figure 2: Antimutagenic effect of A. californica on methyl- $\mathrm{N}^{\prime}$ nitro-N-nitrosoguanidine- (MNNG-) induced mutations on $S$. typhimurium TA100.

3.3. Mutagenesis. Neither extract (LME and SME) induced basepair mutations on S. typhimurium TA100, frameshift mutations on S. typhimurium TA98, nor ROS DNA damage in strain TA102. LME induced a twofold increase of spontaneous mutations at the higher doses ( $1 \mathrm{mg} /$ Petri dish) only with the S9 mixture, but a dose-response curve could not be plotted (Table 1).

3.4. Antimutagenesis. LME and SME exhibited an antimutagenic effect. Mutations induced by MNNG on S. typhimurium TA100 were reduced only when $5 \mu \mathrm{g}$ of mutagen and $250 \mu \mathrm{g}$ of extract were tested which can be seen in Figure 2. In terms of the reduction of mutagenesis against higher mutagen concentrations, $10 \mu \mathrm{g}$ of MNNG was not statistically significant. The reduction of mutagenesis induced by the premutagen 2AA, activated with the S9 mix, was statistically significant $(P<0.001)$, even at the higher dose of premutagen $2 \mathrm{AA}$ (Figure 3). This reduction cannot be considered as a toxic effect because the wrought background on the Petri dishes was not damaged [27]. Reduction of ROS-induced mutations was also observed only when LME or SME were not exposed to higher concentrations of $4 \mathrm{NQO}$ (Figure 4).

\section{Discussion}

Phenolic compounds serve to improve the antioxidant properties of the plants; thus, in the majority of studies, they are correlated with antioxidant capacity [5]. In our study, the highest antioxidant capacity and total phenolic content were presented by SME. Little information concerning the bioactive compounds and antioxidant activities of the stems and leaves of Anemopsis californica grown in Mexico is available. On the other hand, this plant has been widely used and is empirically proven as a medicinal plant. However, there are not many studies on the safety of its use or the effects 


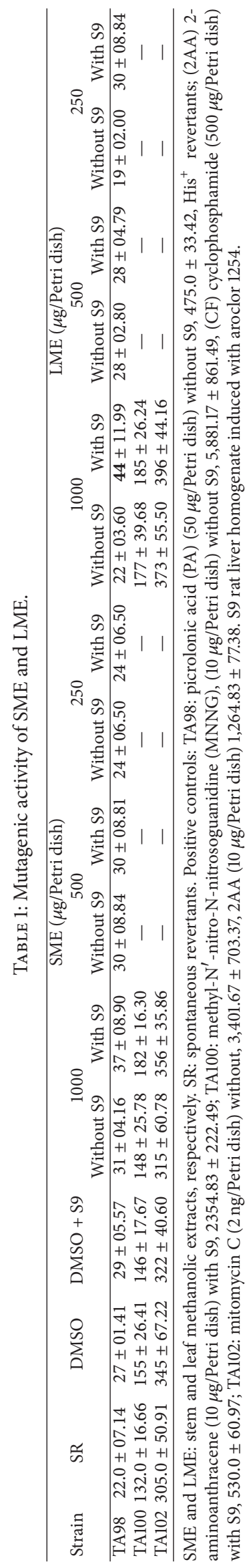




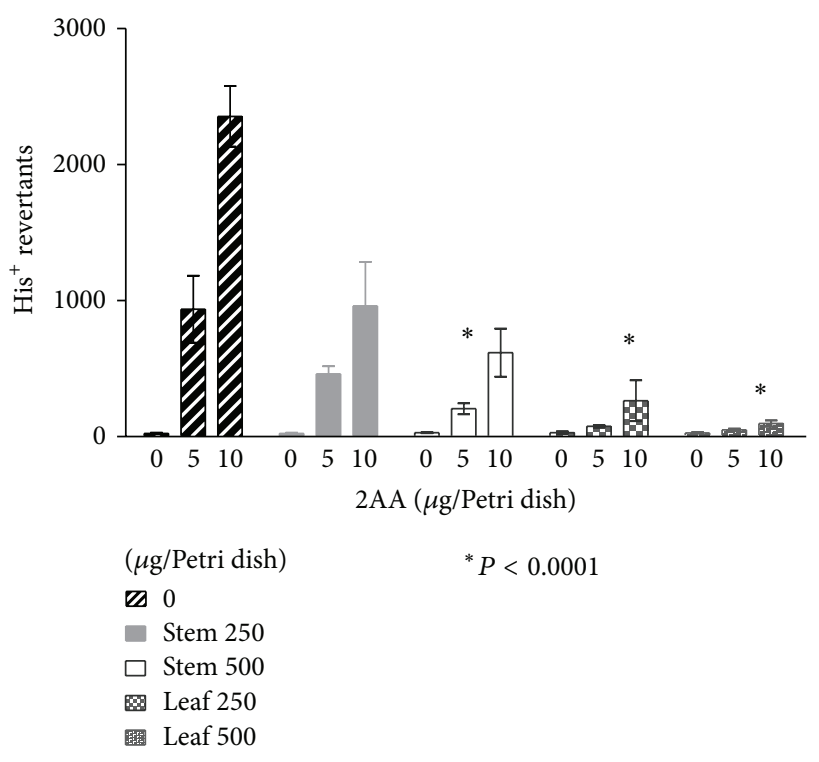

FIgURE 3: Antimutagenic effect of A. californica on 2AA-induced mutations and S. typhimurium TA98.

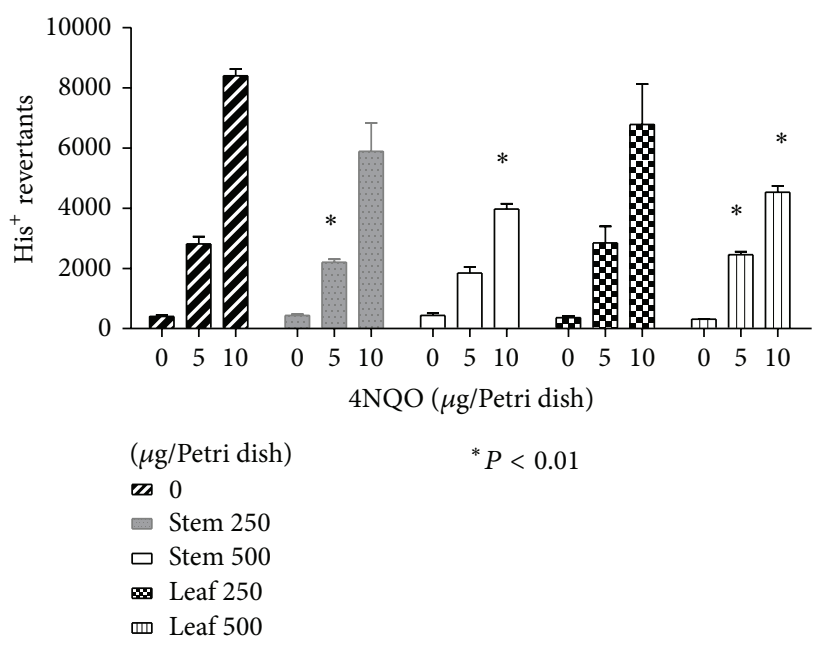

FIgURE 4: Antimutagenic effect of Anemopsis californica on 4NQOinduced mutations on S. typhimurium TA102.

it may have on DNA. The results in this study show that Anemopsis californica did not induce any point mutations in the $S$. typhimurium Ames test. These results suggest that the LME and SME of Anemopsis californica may be safe for use in humans and should be considered for further medical development studies. In fact, the Ames test has been widely recommended as the first tool in the risk-exposure evaluation of therapeutic compounds or mixtures [10]. Mutagenicity evaluation for medical plants must be conducted, because not all naturally occurring compounds are innocuous. Tacca integrifolia Ker-Gawl, a plant used in Southern Asia, was found to be mutagenic on S. typhimurium strains TA98 and TA100. In Taiwan, betel quid, a natural chewing product composed of fresh green areca fruit, Piper betle, and slaked lime paste, is frequently used [32]. However, despite being a natural product, it demonstrated to be mutagenic on S. typhimurium TA100 because it contains N-nitroso guvacoline, an $\mathrm{N}$-nitrosoguanidine. In Chile, it was found that red piper consumption increased gallbladder cancer. Scientific studies demonstrated that red piper was mutagenic on the Ames test and carcinogenic because it contained high doses of aflatoxins. In the present work, we observed that the extracts of A. californica isolated from Querétaro, Mexico, are not mutagenic.

Despite the fact that there are several mutagenic problems among naturally occurring plants used for their medicinal therapeutic properties or as food additives, the majority of these have been reported as antimutagenic rather than genotoxic. Castela texana, an antiamebic plant, was shown not to be mutagenic in the Ames test; in contrast, it is an antioxidant and reduces mutations induced by fluoroquinolones [2]. Rubia cordifolia L. (Rubiaceae) is an important medicinal plant used in Ayurvedic medicine, especially for skin disorders. Rubia cordifolia contains alizarin, which is able to reduce the mutagenicity of $2 \mathrm{AF}$ as observed by the Ames test and damaged DNA induced by 4 NQO on Escherichia coli [33].

In this study, A. californica induced a statistically significant increase $(P<0.001)$ of mutagenic properties in 2AA (Figure 3), a premutagenic compound that is a chemical carcinogen frequently found in air pollution. This significant effect is not considered toxic and no damage was observed on the background wrought in any of the plates. These results suggest that both extracts should be suitable for evaluation concerning CyP450 modulations effects. Another Mexican plant, Heliopsis longipes, and its main compound, affinin, were also able to reduce 2AA-induced mutagenicity [34]. The previous report from Kaur et al. [33] found antimutagenic properties in alizarin from Rubia cordifolia against the similar premutagen 2 -aminofluorene (2AF). These results could be explained by finding that these medical plants might contain compounds capable of inhibiting the CyP450 required for activating these mutagens. In fact, Rodeiro et al. [35] reported that affinin reduced the expression of CyP450, CYP1A1/2, 2D6, and 3A4. In this study, we used aroclor-induced rat liver enzymes that contained CYP, which were necessary for the activation of polycyclic aromatic hydrocarbons.

The activity of this medicinal plant against the alkylating agent MNNG was observed only when the mutagen concentration was not very high ( $<5 \mu \mathrm{g} /$ Petri dish), as illustrated in Figure 2 . These results are slightly different from the previously observed effects of the medicinal plant Rhoeo discolor, which significantly reduced basepair mutations when the ogt gene is present [4]. The compound responsible for the induction of $\mathrm{ogt}$ activity remains unknown.

In this work, we demonstrated that SME and LME of $A$. californica contain a high amount of polyphenols, which may possess several antimutagenic properties as had been reported throughout the literature. Schwarz et al. [36] evaluated that estradiol-dependent cancer might be regulated by polyphenols and the natural extract of St. John's Wort and several natural polyphenols. CYP1A1.1, responsible for estradiol metabolism, was most inhibited by the whole crude extract; the variant CYP1A1.2 (Ile462Val) was significantly more strongly inhibited by the constituents in its pure 
form. $\mathrm{IC}_{50}$ values for 2-hydroxylation were $>2$ times lower compared with the wild-type enzyme and the CYP1A1.4 variant (Thr461Asn). In addition, the inhibition exhibited remarkable region selectivity. The data suggest that the risk of estrogen-mediated diseases might be influenced not only by CYP1A1 genotype-dependent activation, but also by its inhibition by the natural polyphenols in our diet and drugs. In the present work, the whole extract of $A$. californica also shows a significant reduction in the mutagenicity of premutagens requiring CYP-450 metabolisms.

The results presented in this work show that LME and SME of A. californica possess antimutagenic properties against the ROS-generating compound 4NQO on the S. typhimurium TA102 strain. This strain is known to be sensitive to oxidative damage in DNA. It has been very useful in detecting ROS-generating DNA damage. The TA102 strain detects a variety of oxidative mutagens, including X-rays, bleomycin, hydrogen peroxide and other hydroperoxides, and 4-nitroquinoline-1-oxide [37]. Figure 3 shows that these extracts possess some antioxidant components; higher doses of both extracts induced a statistically significant reduction of 4NQO-induced mutagenesis $(P<0.01)$ especially when exposure to the mutagen is $<10 \mu \mathrm{g} /$ Petri dish. This antimutagenic effect could probably be improved if the antioxidant component in these extracts could be purified. In fact, 4NQO is a potent mutagen that generates oxidative damage. It has also been employed as an inducer model of oral carcinogenesis with lymphatic metastasis in mice [38]. Miranda et al. [39] proposed that $4 \mathrm{NQO}$-induced oxidative damage initiated the multistep process causing carcinogenesis in rat tongues. Polyphenols might probably be responsible for these effects. The literature on polyphenol antioxidant properties is abundant. In fact, Petriello et al. [40] recommend the employment of natural plants and plant-derived polyphenols as an alternative to reducing genotoxic risks to environmental pollution.

The antioxidant properties observed in the Ames test against 4NQO-induced mutations were also verified with the determination of antioxidant properties using the DPPH method, depending on the concentration of LME or SME used.

Antioxidant properties have been shown in other antimutagenic plants. It was previously found that Castela texana and Rhoeo discolor have antioxidant properties against the mutagenic effects of the ROS-generating quinolone antibiotics [2, $3]$. It was demonstrated that $4 \mathrm{NQO}$ increased lipid peroxidation and decreased the levels of the nonenzymatic antioxidant compounds, as it reduced glutathione (GSH) and enzymatic antioxidants (superoxide dismutase (SOD), catalase (CAT), glutathione peroxidase (GPx), and glutathione-S-transferase (GST)) in both the liver and kidneys. Spirulina extracts were also antimutagenic against 4NQO-induced ROS damage [41].

\section{Conclusions}

Anemopsis californica did not induce any point mutations on the $S$. typhimurium Ames test, which renders it suitable for further studies because it possesses therapeutic uses.
This medicinal plant has a slight antimutagenic effect against mutations induced by alkylating agents such as MNNG. It could provide protection against exposure to alkylating mutations. Additionally, A. californica as well as other medicinal plants possesses antioxidant properties. Its application could be useful for reducing genotoxic risk by exposure to ROSgenerating exposure. Its most remarkable effect was found to be as an inhibitor of mutagenic induction of premutagens requiring $\mathrm{CyP} 450$, such as $2 \mathrm{AA}$. This property demonstrates that the use of this medicinal plant could provide protection against polycyclic aromatic hydrocarbons which are well known as premutagens and precarcinogens.

\section{Conflict of Interests}

The authors declare that there is no conflict of interests regarding the publication of this paper.

\section{Acknowledgments}

The authors would like to thank Gabriela AguileraHernandez, L. T., for her aid in preparing the chemicals and culture mediums. This work was supported by a grant from the Ministry of Education (Secretaría de Educación Pública, SEP) through the Programa de Mejoramiento del Profesorado (PROMEP). The authors would also like to thank Tina Kim Coop (Peace Corps Volunteer) for her assistance in editing the English language revision of this work.

\section{References}

[1] R. Cariño-Cortés, A. Hernández-Ceruelos, J. M. TorresValencia, M. González-Avila, M. Arriaga-Alba, and E. MadrigalBujaidar, "Antimutagenicity of Stevia pilosa and Stevia eupatoria evaluated with the Ames test," Toxicology in Vitro, vol. 21, no. 4, pp. 691-697, 2007.

[2] M. Reyes-López, S. Villa-Treviño, M. Arriaga-Alba et al., "The amoebicidal aqueous extract from Castela texana possesses antigenotoxic and antimutagenic properties," Toxicology in Vitro, vol. 19, no. 1, pp. 91-97, 2005.

[3] M. González-Avila, M. Arriaga-Alba, M. de La Garza et al., "Antigenotoxic, antimutagenic and ROS scavenging activities of a Rhoeo discolor ethanolic crude extract," Toxicology in Vitro, vol. 17, no. 1, pp. 77-83, 2003.

[4] A. A. Myriam, B. José Luis, R. P. Nancy Jannete, S. N. Jaime, R. S. Roberto, and G. A. Marisela, "Antimutagenicity mechanisms of the Rhoeo discolor ethanolic extract," Experimental and Toxicologic Pathology, vol. 63, no. 3, pp. 243-248, 2011.

[5] W. Xu, L. Liu, B. Hu et al., "TPC in the leaves of 116 sweet potato (Ipomoea batatas L.) varieties and Pushu 53 leaf extracts," Journal of Food Composition and Analysis, vol. 23, no. 6, pp. 599$604,2010$.

[6] M. Déciga-Campos, I. Rivero-Cruz, M. Arriaga-Alba et al., "Acute toxicity and mutagenic activity of Mexican plants used in traditional medicine," Journal of Ethnopharmacology, vol. 110, no. 2, pp. 334-342, 2007.

[7] M. Zahin, F. Aqil, and I. Ahmad, "Broad spectrum antimutagenic activity of antioxidant active fraction of Punica granatum 
L. peel extracts," Mutation Research-Genetic Toxicology and Environmental Mutagenesis, vol. 703, no. 2, pp. 99-107, 2010.

[8] K. Mortelmans and E. Zeiger, "The Ames Salmonella /microsome mutagenicity assay," Mutation Research-Fundamental and Molecular Mechanisms of Mutagenesis, vol. 455, no. 1-2, pp. 29-60, 2000.

[9] K. L. Dobo, N. Greene, M. O. Cyr, S. Caron, and W. W. Ku, “The application of structure-based assessment to support safety and chemistry diligence to manage genotoxic impurities in active pharmaceutical ingredients during drug development," Regulatory Toxicology and Pharmacology, vol. 44, no. 3, pp. 282293, 2006.

[10] M. Arriaga-Alba, R. Montero-Montoya, and J. J. EspinosaAguirre, "The ames test in twenty-first century," Research \& Reviews: A Journal of Toxicology, vol. 2, no. 1, pp. 23-37, 2012.

[11] D. Purves, C. Harvey, D. Tweats, and C. E. Lumley, "Genotoxicity testing: current practices and strategies used by the pharmaceutical industry," Mutagenesis, vol. 10, no. 4, pp. 297312, 1995.

[12] F. Le Curieux, D. Marzin, and F. Erb, "Comparison of three short-erm assays: results on seven chemicals. Potential contribution to the control of water genotoxicity," Mutation Research/Genetic Toxicology, vol. 319, no. 3, pp. 223-236, 1993.

[13] P. A. Munz and D. D. Keck, A California Flora, University of California Press, Oakland, Calif, USA, 1968.

[14] M. Martínez, Catálogo de nombres vulgares y científicos de plantas mexicanas, Fondo de Cultura Económica, Tlalpan, Mexico, 1979.

[15] F. Shreve and I. L. Wiggins, Vegetation and flora of the Sonora Desert, vol. 1-2, Stanford University Press, Palo Alto, Calif, USA, 1964.

[16] R. B. Kaul, "Saururaceae," in Flora of the Great Plains, R. L. McGregor, T. M. Barkley, R. E. Brooks, and E. K. Schofield, Eds., p. 79, University Press of Kansas, Lawrence, Kan, USA, 1986.

[17] R. G. Calderón, Saururaceae. Flora del Bajío y Regiones Adyacentes, vol. 42 of Michoacán, Mexico, Instituto de Ecología, 1996.

[18] E. Argüelles, R. Fernández, and S. Zamudio, "Listado florístico preliminar del estado de Querétaro. Flora del Bajío y de Regiones Adyacentes," Instituto de Ecología, Pátzcuaro, Michoacán, vol. 2, p. 155, 1991.

[19] J. Timbrook, "Virtuous herbs: plants in Chumash medicine," Journal of Ethnobiology, vol. 7, no. 2, pp. 171-180, 1987.

[20] J. Timbrook, "Ethnobotany of chumash indians, California, Based on Collections by John P. Harrington," Economic Botany, vol. 44, no. 2, pp. 236-253, 1990.

[21] F. A. Santos and V. S. Rao, "Antiinflammatory and antinociceptive effects of 1,8 -cineole a terpenoid oxide present in many plant essential oils," Phytotherapy Research, vol. 14, no. 4, pp. 240-244, 2000.

[22] J. D. Adams Jr. and C. Garcia, "Women's health among the Chumash," Evidence-Based Complementary and Alternative Medicine, vol. 3, no. 1, pp. 125-131, 2006.

[23] A. L. Daniels, S. van Slambrouck, R. K. Lee et al., "Effects of extracts from two native American plants on proliferation of human breast and colon cancer cell lines in vitro," Oncology Reports, vol. 15, no. 5, pp. 1327-1331, 2006.

[24] C. N. Kaminski, S. L. Ferrey, T. Lowrey, L. Guerra, S. van Severine, and W. F. A. Steelant, "In vitro anticancer activity of Anemopsis Californica," Oncology Letters, vol. 1, no. 4, pp. 711715,2010
[25] A. L. Medina, M. E. Lucero, F. O. Holguin et al., "Composition and antimicrobial activity of Anemopsis californica leaf oil," Journal of Agricultural and Food Chemistry, vol. 53, no. 22, pp. 8694-8698, 2005.

[26] A. L. Medina-Holguín, F. O. Holguín, S. Micheletto, S. Goehle, J. A. Simon, and M. A. O'Connell, "Chemotypic variation of essential oils in the medicinal plant Anemopsis californica," Phytochemistry, vol. 69, no. 4, pp. 919-927, 2008.

[27] D. M. Maron and B. N. Ames, "Revised methods for the Salmonella mutagenicity test," Mutation Research, vol. 113, no. 3-4, pp. 173-215, 1983.

[28] P. Molyneux, "The use of the stable radical diphenylpicrylhydrazyl (DPPH) for estimating antioxidant activity," Songklanakarin Journal of Science and Technology, vol. 26, no. 2, pp. 211-219, 2004.

[29] V. L. Singleton, R. Orthofer, and R. M. Lamuela-Raventós, "Analysis of total phenols and other oxidation substrates and antioxidants by means of folin-ciocalteu reagent," Methods in Enzymology, vol. 299, pp. 152-178, 1999.

[30] L. M. Magalhães, F. Santos, M. A. Segundo, S. Reis, and J. L. F. C. Lima, "Rapid microplate high-throughput methodology for assessment of Folin-Ciocalteu reducing capacity," Talanta, vol. 83, no. 2, pp. 441-447, 2010.

[31] M. M. Lesjak, I. N. Beara, D. Z. Orčić et al., "Juniperus sibirica Burgsdorf as a novel source of antioxidant and antiinflammatory agents," Food Chemistry, vol. 124, no. 3, pp. 850856, 2011.

[32] A. R. Mohd-Fuat, E. A. Kofi, and G. G. Allan, "Mutagenic and cytotoxic properties of three herbal plants from Southeast Asia," Tropical Biomedicine, vol. 24, pp. 49-59, 2007.

[33] P. Kaur, M. Chandel, S. Kumar, N. Kumar, B. Singh, and S. Kaur, "Modulatory role of alizarin from Rubia cordifolia L. against genotoxicity of mutagens," Food and Chemical Toxicology, vol. 48, no. 1, pp. 320-325, 2010.

[34] M. Arriaga-Alba, M. Y. Rios, and M. Déciga-Campos, "Antimutagenic properties of affinin isolated from Heliopsis longipes extract," Pharmaceutical Biology, vol. 51, no. 8, pp. 1035-1039, 2013.

[35] I. Rodeiro, M. T. Donato, N. Jimenez et al., "Inhibition of human P450 enzymes by natural extracts used in traditional medicine," Phytotherapy Research, vol. 23, no. 2, pp. 279-282, 2009.

[36] D. Schwarz, P. Kisselev, W. Schunck, and I. Roots, "Inhibition of $17 \beta$-estradiol activation by CYP1A1: genotype- and regioselective inhibition by St. John's Wort and several natural polyphenols," Biochimica et Biophysica Acta, vol. 1814, no. 1, pp. 168-174, 2011.

[37] D. E. Levin, M. Hollstein, M. F. Christman, E. A. Schwiers, and B. N. Ames, "A new Salmonella tester strain (TA102) with A.T base pairs at the site of mutation detects oxidative mutagens," Proceedings of the National Academy of Sciences of the United States of America, vol. 79, no. 23, pp. 7445-7449, 1982.

[38] J. Li, F. Liang, D. Yu, H. Qing, and Y. Yang, "Development of a 4-nitroquinoline-1-oxide model of lymph node metastasis in oral squamous cell carcinoma," Oral Oncology, vol. 49, no. 4, pp. 299-305, 2013.

[39] S. R. Miranda, J. Noguti, J. G. Carvalho, C. T. F. Oshima, and D. A. Ribeiro, "Oxidative DNA damage is a preliminary step during rat tongue carcinogenesis induced by 4-nitroquinoline 1-oxide," Journal of Molecular Histology, vol. 42, no. 2, pp. 181186, 2011. 
[40] M. C. Petriello, B. J. Newsome, T. D. Dziubla, J. Z. Hilt, D. Bhattacharyya, and B. Hennig, "Modulation of persistent organic pollutant toxicity through nutritional intervention: emerging opportunities in biomedicine and environmental remediation," Science of the Total Environment, vol. 491-492, pp. 11-16, 2014.

[41] V. P. Viswanadha, S. Sivan, and R. Rajendra Shenoi, "Protective effect of Spirulina against 4-nitroquinoline-1-oxide induced toxicity," Molecular Biology Reports, vol. 38, no. 1, pp. 309-317, 2011. 